\title{
RETALHO PEDICULAdO DE LÍNGUA PARA tRATAMENTO DE COMUNICAÇÃO BUCONASOSINUSAL SEVERA
}

Leonardo Silva BENATO, Kelston GOMES, Thiago JONASSON, Mauricio ROMANOWSKI, João Luiz CARLINI

O objetivo desse trabalho é apresentar uma abordagem cirúrgica para 0 tratamento de grandes comunicações buconasosinusais adquiridas, principalmente, após ressecção de tumores maxilofaciais.. Paciente do sexo feminino apresentou-se ao CAIF encaminhada de outra instituição para tratamento de grande comunicação buconasosinusal, adquirida após tratamento de tumor odontogênico com hemimaxilectomia. Após preparo préoperatório, a paciente foi submetida a procedimento cirúrgico, sob anestesia geral, para fechamento da fístula utilizando-se um retalho pediculado de língua com base na porção anterior da mesma. O retalho foi mantido pediculado durante 03 semanas, período necessário para integração do enxerto na área receptora. Após esse período, realizou-se novo procedimento sob anestesia geral para soltar o pedículo e moldar o enxerto de tecido mole ao palato. Observou-se no pós-operatório da segunda intervenção, boa integração do enxerto de língua ao palato, fechamento da fístula palatina, permanecendo somente pequeno orifício residual comunicando com a cavidade nasal. Observou-se ainda melhora de funções como dicção das palavras, deglutição e desaparecimento do som anasalado da fala. A técnica mostrou-se efetiva para o tratamento de grandes fístulas palatinas. O próximo passo do tratamento, com reconstrução óssea da maxila poderá ser realizada, uma vez que existe tecido mole para o recobrimento do enxerto ósseo.

Palavras-chave: Retalhos Cirúrgicos; Comunicação; Fístula bucal 